\title{
Optimizing ceftolozane-tazobactam dosage during continuous renal replacement therapy: some nuances
}

\author{
Gerardo Aguilar ${ }^{1,2,3^{*}}$ (D), Rafael Ferriols $2,3,4$, Sara Martínez-Castro ${ }^{1}$, Carlos Ezquer ${ }^{3,4}$, Ernesto Pastor ${ }^{1}$, Jose A. Carbonell ${ }^{1}$, \\ Manuel Alós $2,3,4$ and David Navarro 2,3,5
}

We have read the recent letter by Honore et al. [1] about our findings published in this journal regarding the influence of continuous renal replacement therapy (CRRT) on the pharmacokinetics of ceftolozane-tazobactam (C/ T) [2]. In our report, we decided to administer a $3 \mathrm{~g} / \mathrm{iv}$ dose every $8 \mathrm{~h}$ taking into account two previous studies referenced in our paper [2] and another one which showed CRRT to be an independent predictor of clinical failure (OR 4.5, 95\% CI 1.18-17.39, $p=0.02)$ when $\mathrm{C} / \mathrm{T}$ is administered at $1.5 \mathrm{~g}$ every $8 \mathrm{~h} \mathrm{[3].}$

As Honore et al. explain in their paper, the $\mathrm{C} / \mathrm{T}$ eliminitation was assumed by hemodiafiltration and the adsorption was not assessed [1]. However, there is a misunderstanding in this letter [1], because we used a polysulphone membrane (Fresenius, Germany) instead of an acrylonitrile 69 Multiflow (AN-69-M). In contrast to highly adsorptive membranes (HAM; e.g., AN69 surface-treated, AN69-ST), the antibiotic adsorption with polysulphone ones is negligible, which facilitates antibiotic adaptation during CRRT [4].

Our data should not be extrapolated to other clinical scenarios, as noted by Honore et al. [1]. In our report, ceftolozane and tazobactam plasma concentrations remained above the minimal inhibitory concentration (MIC), for MICs of up to $8 \mu \mathrm{g} / \mathrm{mL}$, but we estimated that the administration of standard doses of $1 \mathrm{~g} / 0.5 \mathrm{~g}$, even with polysulphone membranes, could compromise the effectiveness of $\mathrm{C} / \mathrm{T}$ for not reaching adequate tazobactam concentrations. Thus, the use of HAM would represent a real risk factor of clinical failure when a $\mathrm{C} / \mathrm{T}$ dose of $1.5 \mathrm{~g}$ every $8 \mathrm{~h}$ is administered, especially in

\footnotetext{
* Correspondence: gerardo.aguilar@uv.es

This reply refers to the comment available at: https://doi.org/10.1186/s13054019-2692-2.

${ }^{1}$ Critical Care Unit, Anesthesiology and Critical Care Department, Hospital

Clínico Universitario de Valencia, Valencia, Spain

${ }^{2}$ INCLIVA Health Research Institute, Avenida de Menéndez y Pelayo, 4, 46010

Valencia, Spain

Full list of author information is available at the end of the article
}

multidrug-resistant infections [3]. Therefore, we agree with Honore et al. [1] that therapeutic drug monitoring (TDM) is critical when using $\mathrm{C} / \mathrm{T}$ for patients receiving CRRT, especially when MICs of bacteria like multidrugresistant (MDR) Pseudomonas aeruginosa are considered very high. However, the recommendation of continuous (over $24 \mathrm{~h}$ ) vs extended (over 2 to $4 \mathrm{~h}$ ) or intermittent (over 30 to $60 \mathrm{~min}$ ) infusion of beta-lactams is still under debate [5].

\section{Abbreviations \\ AN-69-M: Acrylonitrile 69 Multiflow; AN-69-ST: AN69-surface treated; C/ T: Ceftolozane-tazobactam; CRRT: Continuous renal replacement therapy; HAM: Highly adsorptive membranes; MDR: Multidrug-resistant; MIC: Minimal inhibitory concentration}

\section{Acknowledgements}

None

\section{Authors' contributions}

GA, RF, and DN designed the paper. All authors participated in drafting and reviewing the manuscript. All authors read and approved the final version of the manuscript.

\section{Funding}

None.

Availability of data and materials

Not applicable.

Ethics approval and consent to participate

Not applicable.

\section{Consent for publication}

Not applicable.

\section{Competing interests}

The authors declare that they have no competing interests.

\section{Author details}

${ }^{1}$ Critical Care Unit, Anesthesiology and Critical Care Department, Hospital Clínico Universitario de Valencia, Valencia, Spain. ${ }^{2}$ INCLIVA Health Research Institute, Avenida de Menéndez y Pelayo, 4, 46010 Valencia, Spain. ${ }^{3}$ School of Medicine, University of Valencia, Avenida Blasco Ibáñez, 15, 46010 Valencia, Spain. ${ }^{4}$ Department of Pharmacy, Hospital Clínico Universitario de Valencia, Avenida Blasco Ibáñez, 17, 46010 Valencia, Spain. ${ }^{5}$ Department of 
Microbiology, Hospital Clínico Universitario de Valencia, Avenida Blasco Ibáñez, 17, 46010 Valencia, Spain.

Received: 22 December 2019 Accepted: 27 December 2019

Published online: 10 January 2020

\section{References}

1. Honore PM, Mugisha A, Gutierrez LB, Redant S, Kaefer K, Gallerani A, De Bels D. Optimizing ceftolozane-tazobactam dosage during continuous renal replacement therapy: additional insights. Crit Care. 2019;23(1):406.

2. Aguilar G, Ferriols R, Martínez-Castro S, Ezquer C, Pastor E, Carbonell JA, Alós M, Navarro D. Optimizing ceftolozane-tazobactam dosage in critically ill patients during continuous venovenous hemodiafiltration. Crit Care. 2019; 23(1):145.

3. Bassetti M, Castaldo N, Cattelan A, Mussini C, Righi E, Tascini C, et al. Ceftolozane/tazobactam for the treatment of serious $P$. aeruginosa infections: a multicenter nationwide clinical experience. Int J Antimicrob Agents. 2019 Apr;53(4):408-15.

4. Honore PM, Spapen HD. What a clinician should know about a renal replacement membrane? J Transl Intern Med. 2018;6:62-5.

5. Lee YR, Miller PD, Alzghari SK, Blanco DD, Hager JD, Kuntz KS. Continuous infusion versus intermittent bolus of beta-lactams in critically ill patients with respiratory infections: a systematic review and meta-analysis. Eur J Drug Metab Pharmacokinet. 2018;43(2):155-70.

\section{Publisher's Note}

Springer Nature remains neutral with regard to jurisdictional claims in published maps and institutional affiliations. 